Vol. 6, $n^{\circ} 1 \mid 2002$

Varia

\title{
L'abolition de la peine de mort en France : le rendez-vous manqué de 1906-1908
}

Julie Le Quang Sang

\section{OpenEdition}

Édition électronique

URL : https://journals.openedition.org/chs/234

DOI : $10.4000 /$ chs. 234

ISSN : 1663-4837

Éditeur

Librairie Droz

Édition imprimée

Date de publication : 1 juillet 2002

Pagination : $57-83$

ISBN : 2-600-00803-9

ISSN : 1422-0857

\section{Référence électronique}

Julie Le Quang Sang, «L'abolition de la peine de mort en France : le rendez-vous manqué de

1906-1908 », Crime, Histoire \& Sociétés / Crime, History \& Societies [En ligne], Vol. 6, nº 1 | 2002, mis en ligne le 29 avril 2009, consulté le 22 mars 2022. URL : http://journals.openedition.org/chs/234 ; DOI https://doi.org/10.4000/chs.234

Ce document a été généré automatiquement le 22 mars 2022.

(c) Droz 


\title{
L'abolition de la peine de mort en France : le rendez-vous manqué de 1906-1908
}

\author{
Julie Le Quang Sang
}

1 Après une histoire mouvementée et bien des vicissitudes, la peine capitale a été abrogée en France en 1981. Si cet épilogue a fait l'objet de nombreux commentaires, on connaît moins l'épisode des années 1906-1908. Ce fut, pourtant, sous la III République qu'eut lieu le premier et dernier grand débat d'ensemble sur la question ${ }^{2}$ et il s'en fallut de peu que la guillotine fût supprimée. Ce fut, en effet, à la suite du dépôt d'un amendement des députés socialistes Constans et Allard tendant à la suppression des crédits affectés au bourreau le 10 décembre 1905 que s'ouvrit un débat général sur le problème de la peine de mort. Repoussé par le rapporteur du budget de la justice, Cruppi, et le ministre de la Justice de l'époque, Chaumié, le texte fut désapprouvé, en 1906, par le ministre de la Justice, Guyot-Dessaigne, qui refusait toute abolition détournée. L'amendement fut rejeté par 311 voix contre 172. Alors que le ministre de la Justice s'était engagé, le 30 juillet 1906, à étudier une refonte de l'échelle des peines, la commission du budget émit une proposition similaire à celle de Constans et Allard. Finalement, le gouvernement et la commission s'accordèrent sur l'idée que la question serait réservée, jusqu'à ce que la Chambre des députés se fût prononcée sur l'abrogation de la peine capitale. Toutefois, un amendement déposé par Castillard et le comte du Périer de Larsan (rétentionnistes ${ }^{3}$ ) tendant au rétablissement des crédits fut adopté par 247 voix contre 235 sur 482 votants ${ }^{4}$. Le 5 novembre 1906, Guyot-Dessaigne déposa un projet qui préconisait l'abolition de la peine de mort, « excepté dans les cas où elle est édictée par les codes de justice militaire pour les crimes commis en temps de guerre », et son remplacement par une peine d'internement perpétuel. Assorti au choix d'aboutir à une abolition complète et de droit, son dépôt constitua le prélude à l'avortement du texte sur la scène parlementaire: la peine capitale avait failli être abolie de fait en France. Dans un premier temps, l'activisme des abolitionnistes sembla obtenir quelque succès. À la proposition Reinach (radical) succéda une proposition similaire de Meunier (gauche modérée) en juillet 1906. Et le premier rapport de la commission abondait dans 
le sens du gouvernement (rapport Cruppi, 22 octobre 1907). Mais l'inversion du rapport de force au profit des rétentionnistes fit échouer le projet, malgré un débat passionné à la Chambre des députés sur la peine de mort d'abord, la peine de substitution ensuite.

$\mathrm{Si}$, comme $\mathrm{Nye}^{5}$, on peut se demander pourquoi et comment la strate la plus privilégiée des avocats (radicaux, socialistes), qui porta l'abrogation de la peine capitale, fut mis en échec par d'autres avocats (droites républicaine et nationaliste), on peut surtout s'interroger, comme Machelon ${ }^{6}$, sur la question de savoir pourquoi la III République, d'ordinaire considérée comme un Âge d'or des libertés,a, paradoxalement, voté à la fois autant de lois favorables aux libertés ${ }^{7}$ et écarté le projet d'abolition. En position hégémonique à partir de 1906, les avocats impulsèrent les grandes lois fondatrices du régime républicain (réformes scolaires, loi de Séparation de l'Église et de l'État, reconnaissance des grandes libertés publiques, etc.), autant de réformes qui témoignèrent d'une vision spécifique du politique, imprégnée de la croyance dans les vertus sacrées de la loi comme instrument de régulation politique et sociale ${ }^{8}$. Ce même

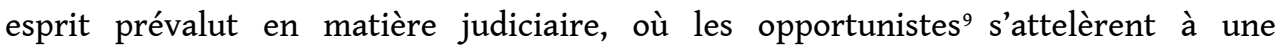
réorganisation du système. Loin des déclarations d'intention proclamées lors de la campagne électorale de 1869 , la refonte du système ne se solda que par une ébauche de réalisation. À côté des réformes partielles, nombre de tentatives en matière de réorganisation judiciaire et de protection de la liberté individuelle n'aboutirent pas, comme en témoignèrent, par exemple, les réformes de la magistrature, de la détention préventive, du code d'instruction criminelle, des codes pénal et de procédure pénale militaires. Plus encore, les républicains combattirent toute forme d'atteinte aux valeurs bourgeoises : prostitution, mendicité, vagabondage, récidive. Des lois pénales furent promulguées pour réprimer une délinquance en voie d'expansion. Si la République s'attela, à partir de 1875, à la réforme des prisons, afin de promouvoir l'amendement, elle s'attacha, à partir de 1882, à les vider des vagabonds et des voleurs récidivistes pour mieux éliminer les incorrigibles tout en évitant au maximum les emprisonnements. La progression inquiétante de la récidive ${ }^{10}$, l'échec de la politique impériale ${ }^{11}$ et du régime cellulaire et les prises de position de spécialistes (magistrats, jurisconsultes, pénalistes, pénitentiaristes, criminologues) et d'hommes d'État ${ }^{12}$ amenèrent les opportunistes à voter une loi sur la relégation des multirécidivistes ${ }^{13}$, peu après la réélection de Ferry $\left(27\right.$ mai 1885) ${ }^{14}$. Mesure d'éloignement du territoire, la relégation, surnommée la "guillotine sèche ", tendait à éliminer les "incorrigibles ", en l'espèce les auteurs de cette petite récidive à répétition qui n'était pas prévue par le code Napoléon. La politique criminelle s'articula autour de la notion de dangerosité sociale d'un côté, de prévention de l'autre ${ }^{15}$. Outre qu'il convenait d'armer le juge d'une loi dissuasive pour neutraliser efficacement cette catégorie particulière d'infracteurs, il importait de prévenir toute possible dérive du délinquant primaire en lui donnant un avertissement solennel sous la forme du sursis, en encourageant son amélioration morale par la libération conditionnelle et en facilitant sa réinsertion sociale grâce aux sociétés de patronage ${ }^{16}$. On vit, dès lors, se profiler une nouvelle économie pénale ${ }^{17}$, dont le centre de gravité restait la dissuasion par la peine (avec une tendance à réduire l'emprisonnement par le sursis), auquel s'adjoignaient l'élimination des « incorrigibles» d'un côté, et la surveillance des «corrigibles» de l'autre ${ }^{18}$. Contre toute attente, toutefois, la relégation conduisit les magistrats à alléger les peines des petits délinquants, le nombre des relégués tendant à s'abaisser d'année en année... Alors que la peine de mort semblait être seule à pouvoir pallier "l'obsession de la 
récidive $»^{19}$ et les carences des pénalités existantes, les radicaux réactivèrent le volet relatif à l'abrogation, dans la droite ligne des Constituants... en vain.

En effet, si jusqu'en 1907, les abolitionnistes pouvaient escompter un certain succès, avec une offensive conjuguée de leurs partisans à la Chambre des députés, on assista, à partir de cette date, à un revirement du rapport de force esquissé en 1906 et à la victoire des partisans de la peine de mort, dans un contexte d'agitation politique et sociale (1) et de mobilisation rétentionniste. Sous la pression de nombreux jurys et leurs alliés (2), d'un grand organe de presse populaire (3) et de la frange supérieure des médecins (4), le projet du gouvernement avorta (5).

\section{Un contexte politique et social troublé}

De 1899 à 1905, la France fut gouvernée par une coalition de gauche composée des modérés de l'Alliance démocratique ${ }^{20}$, des radicaux ${ }^{21}$ et des socialistes (le Bloc). À l'issue des élections législatives des 27 avril-11 mai 1902, le Bloc sortit vainqueur. Au total, la gauche se renforça ou resta stable dans les départements à forte densité industrielle, à l'exception de la Seine-Inférieure, enjeu d'importance dans la mobilisation rétentionniste. Mais la victoire du Bloc s'accompagna vite de tensions internes, globalement hostiles aux socialistes. L'agitation cléricale et ouvrière, le développement du syndicalisme révolutionnaire contribuèrent à faire vaciller la coalition sur sa droite, puis à la faire voler en éclats. Dans ce contexte, les radicaux accédèrent triomphalement au pouvoir lors des élections présidentielles et législatives de 1906.

Dans le climat passionnel faisant suite à la politique anticléricale ${ }^{22}$ poursuivie par les radicaux au début du siècle (loi de Séparation de l'Église et de l'État, 9 décembre 1905), la crise des Inventaires servit de prétexte au conflit. Le 2 janvier 1906, l'administration fiscale, procédant à l'inventaire des biens ecclésiastiques, enjoignit à ses agents de demander aux prêtres l'ouverture des tabernacles. Des incidents eurent lieu dès février 1906, avec pour objectif affiché la défense symbolique de l'Église, temple sacré. L'intervention de Rome, le 11 février 1906, contribua à alimenter l'activisme ultramontain. Finalement, la querelle se solda par la démission du ministère Rouvier et son remplacement par le cabinet Sarrien. Deux événements majeurs accompagnèrent l'arrivée de la nouvelle équipe dirigeante: Clemenceau fit sa rentrée politique en obtenant le portefeuille de l'Intérieur et Briand, le rapporteur de la loi de Séparation de l'Église et de l'État, fut nommé ministre pour la première fois ${ }^{23}$. Le 16 mars 1906, dans un contexte préélectoral, Clemenceau invita les préfets à suspendre les inventaires des biens ecclésiastiques, afin d'éviter tout recours à la force. Cette décision préluda à l'apaisement des esprits, puis à l'arrêt des incidents ${ }^{24}$. La mise à l'écart du "péril clérical » ne sonna pas pour autant le glas des épreuves qui attendaient le pouvoir en place. Relayant l'agitation catholique, l'organisation d'un mouvement syndical et ouvrier et d'un parti socialiste unifié, capables de canaliser le mécontentement né de l'industrialisation, apparurent comme des forces avec lesquelles le gouvernement se devait désormais de compter.

6 Les grèves culminèrent pour atteindre leur apogée en 1904-1907. À l'action du prolétariat industriel (grève des ouvriers électriciens, mars 1907) se joignirent des fractions non négligeables de la paysannerie, de la petite bourgeoisie et de la fonction publique (agents de police de Lyon, 1905; sous-agents des PTT de Paris, 1906) ${ }^{25}$. Durement réprimées, certaines de ces actions entraînèrent la révocation des 
fonctionnaires récalcitrants. L'absence de projet de statut commun tout au long de la période ne fit qu'aiguiser les frustrations. En 1907, alors que le rapport de force à la Chambre des députés s'inversait en faveur des rétentionnistes, la mévente du vin, la baisse des salaires, voire le chômage, ne firent qu'exacerber le mécontentement existant. Si les troubles affectèrent surtout le département de la Seine, ils gagnèrent également la province ${ }^{26}$. Les incidents, violents, perdurèrent jusqu'en 1908. Alors que des affrontements à Draveil se soldèrent par deux morts et dix blessés le 2 juin 1908, une grève dans le secteur du bâtiment à Villeneuve Saint-Georges provoqua quatre morts et des centaines de blessés et l'arrestation de presque tous les responsables de la CGT (Confédération générale du travail). Alors que ces événements furent l'occasion pour nombre de radicaux de demander la dissolution du syndicat, ils encouragèrent les organisations professionnelles à flétrir la politique répressive du gouvernement Clemenceau. Du début de l'année 1907 jusqu'à l'automne 1908, les socialistes relayèrent ces attaques à la Chambre des députés. Les radicaux devaient désormais prendre en considération une force politique naissante : le parti socialiste unifié (26 avril 1905). Dans ce contexte, ils voulurent faire consacrer par le droit un projet à très forte charge idéologique, l'abolition de la peine de mort.

7 Le 17 janvier 1906, Armand Fallières, ancien président du Sénat, sénateur radical du Lot-et-Garonne, fut élu à la Présidence de la République par 449 voix contre 371 au président de la Chambre des députés, Paul Doumer. Les élections législatives des 6 et 20 mai 1906 confirmèrent la victoire du radicalisme. Clemenceau fut promu à la présidence du Conseil le 25 octobre 1906. Forts de leur victoire, Fallières, Clemenceau et les ministres de la Justice successifs Guyot-Dessaigne et Briand reprirent le flambeau des libertés que tant de libéraux et de républicains avaient brandi avant eux. Pour la plupart issus du milieu judiciaire (à l'exception de Clemenceau, médecin, GuyotDessaigne étant magistrat, Fallières et Briand avocats), tous avaient participé à de nombreux ministères, dont celui, décisif, de la Justice. Issus de la même génération et disposant d'un certain renom, ils étaient à une période-clé de leur carrière politique. Si certains étaient en milieu ou en fin de carrière (Fallières, Clemenceau, GuyotDessaigne), d'autres n'étaient arrivés que depuis peu en politique (Briand). Clemenceau était l'une des figures emblématiques du parti radical, qu'il avait contribué à fonder et dont il était rapidement apparu comme l'une des personnalités dominantes. Nommé ministre de l'Intérieur en mars 1906, il savourait alors, pour la première fois, à soixante-cinq ans, les honneurs de la République. Ce fut à Guyot-Dessaigne qu'incomba la responsabilité de mettre en œuvre le programme radical dans le domaine judiciaire. Son décès prématuré, en décembre 1907, temps fort du débat sur la peine de mort, entraîna la nomination de Briand, qui poursuivit son combat. Ancien rapporteur de la loi de Séparation de l'Église et de l'État, fondateur de la SFIO ${ }^{27}$ avec Jaurès et député de Saint-Étienne (1902-1919), puis de la Loire-inférieure, il occupa des fonctions importantes au sein du gouvernement ${ }^{28}$ tout au long de la III République et fit l'une des plus belles carrières politiques ${ }^{29}$ jusqu'en mai 1931 , lorsque la montée de la droite et de l'extrême droite entrava sa réussite aux élections présidentielles.

Même si l'instabilité qui avait prévalu en début de période avait eu pour effet d'émousser la légitimité des promoteurs du projet d'abrogation de la peine capitale, elle leur avait offert une opportunité de réactiver les valeurs les plus prégnantes de la République, dans le droit fil de l'héritage républicain de 1791. Le temps était venu de ressouder leurs rangs autour d'un programme de défenserépublicaine. Si le rapport de force semblait favorable aux abolitionnistes, il ne devait pas le rester longtemps, leurs 
intérêts venant heurter ceux d'autres groupes capables de faire efficacement contrepoids au projet d'abrogation.

\section{La campagne de protestation des jurys}

Associée à l'usage systématique du droit de grâce par le Président Fallières depuis 1906, l'augmentation de la délinquance fut le prétexte pour les rétentionnistes de déclencher un mouvement auquel une fraction des magistrats prirent une part active. Alliés à d'autres groupes, des jurys orchestrèrent une campagne de pétitions et de condamnations, à la suite du viol et du meurtre d'une enfant par un dénommé Soleilland en janvier 1907.

L'arrivée des républicains au pouvoir consacra la montée en puissance des "classes moyennes ", aux dépens des anciens notables. Déjà, la part des professions libérales était importante. Avocats et médecins côtoyaient journalistes, petits et moyens fonctionnaires, instituteurs et professeurs. Par ses origines sociales toutefois, ce nouveau personnel politique se distinguait nettement de la haute fonction publique, qui continuait à être recrutée parmi les anciens notables. Face à ces classes moyennes, les grands corps de l'État (Conseil d'État, Inspection des finances, Cour des comptes, magistrature) étaient issus de la haute bourgeoisie et de l'aristocratie. Or, personnel politique et haute fonction publique contrôlaient tous deux des fonctions essentielles de l'appareil d'état ${ }^{30}$. Dès 1879 , le gouvernement envisagea l'épuration de la magistrature, accusée de conservatisme et de fidélité au régime de Napoléon III. Autant dire que, depuis cet épisode, les relations entre le politique et le judiciaire étaient difficiles. Ceux qui, naguère, avaient affiché leur intransigeance en prenant position pour une épuration d'envergure étaient à présent au pouvoir. Si l'on en croit Lombard, pour qui «le jury n'est qu'un argument-prétexte » dans le conflit latent qui opposait les protagonistes, l'hostilité des jurys au projet d'abolition pourrait être la traduction d'une réaction d'une partie de la magistrature contre les radicaux. Ce fut, en tout cas, de connivence avec des magistrats que des jurés se mobilisèrent, les vœux des jurys étant retransmis à la Chancellerie par des magistrats des Cours d'assises ${ }^{31}$. En revanche, des rapports plus heureux liaient des juges à certains notables de province. L'histoire des jurys ${ }^{32}$ montre d'ailleurs que des élus locaux étaient souvent intervenus pour défendre ces professionnels du droit contre les intrusions du pouvoir politique au sein $\mathrm{du}$ jury $^{33}$. Or, nombreuses furent les assemblées locales (départementales ou municipales) qui se rallièrent au mouvement en 1905-1908. Porte-parole d'une petite bourgeoisie apeurée par l'accroissement de la délinquance, des chambres de commerce et des syndicats de commerçants et d'artisans pouvaient, eux aussi, avoir des raisons de se lancer avec ferveur dans la bataille. Quant aux jurés, ils provenaient, le plus souvent, de cette petite et moyenne bourgeoisie de négociants, marchands, propriétaires, artisans et commerçants, qui craignaient pour leurs biens et se montraient réceptifs au thème de l'insécurité.

11 L'hostilité de nombreux jurys et de leurs alliés se traduisit principalement par l'envoi de pétitions au ministère de la Justice et une augmentation des condamnations à mort. $\mathrm{Du}$ reste, pétitions de jurés, de conseils généraux, de syndicats d'agriculteurs, de commerçants, d'industriels ou de particuliers, avaient commencé à se multiplier dès 1905-1906 $3^{34}$. À Marseille en 1906 et 1907, de nombreux organismes, dont la chambre de commerce, l'Association des syndicats patronaux, la Société pour la défense du commerce et de 
l'industrie et le Syndicat des propriétaires, organisèrent réunions et pétitions contre l'insécurité35. À partir de 1907, certains groupes de pression (Protestation publique et populaire, Ligues de protection sociale et de la sécurité publique) virent le jour ${ }^{36}$. Trois temps ponctuèrent la campagne : une amorce au début de 1907; une reprise au printemps et à l'automne de 1907; une moindre participation, annonciatrice d'un étiolement du mouvement, en 1908.

La résistance s'exprima dès janvier 1907, peu après le crime de Soleilland. La mobilisation atteignit alors des sommets, puisque dix-neuf jurys adressèrent des pétitions au ministre de la Justice. Le fait divers permit d'alimenter la chronique tout en présentant le mouvement comme une " réaction » des jurés contre l'usage abusif du droit de grâce par le Président Fallières, alors qu'il ne lui servait que de prétexte. Allié au jury des Bouches-du-Rhône, le jury de la Seine fit ainsi publier une pétition dans le Matin, selon laquelle :

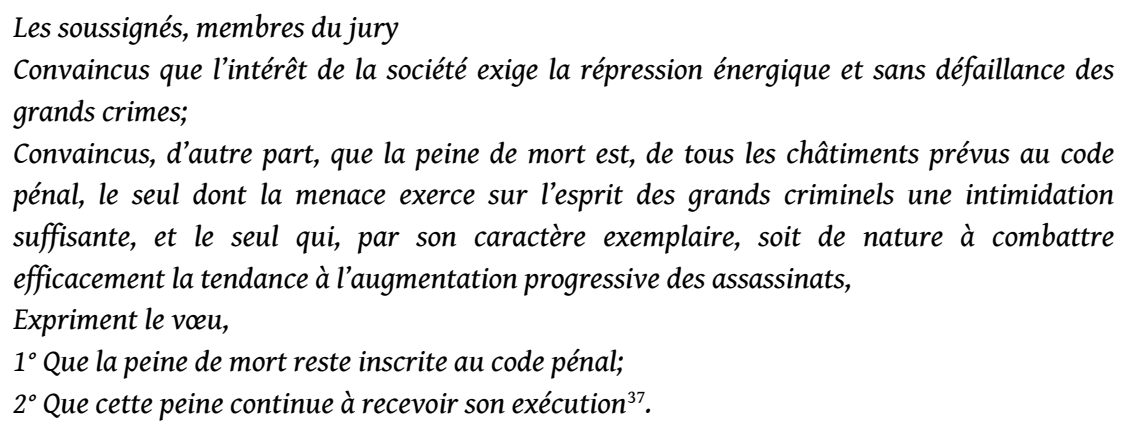

Du printemps à la fin de 1907, la mobilisation se poursuivit, à telle enseigne que le ministre de la Justice crut bon d'ouvrir une enquête auprès de la préfecture de police et de certaines cours d'appel (septembre 190738. Ni les jours fériés, ni les vacances ne suffirent à calmer la ferveur des jurys qui protestaient, tantôt contre la grâce de Soleilland (mai 1907), tantôt contre le rapport de l'abolitionniste Cruppi (octobre 1907), tantôt contre la circulaire du ministère de la Justice visant à interdire l'envoi de pétitions à la Chancellerie :
Mon attention a été appelée à diverses reprises sur des pétitions qu'à l'issue ou au cours des sessions d'assises, des membres de plusieurs jurys criminels m'ont adressé au sujet du maintien de la peine de mort, qui leur paraît exigée par une prétendue recrudescence de la grande criminalité. Dans le cas où de semblables manifestations viendraient à se produire, je vous prie de bien vouloir inviter MM. les présidents des Cours d'Assises de votre ressort à porter à la connaissance de leurs auteurs que les compte rendus de l'administration de la justice criminelle publiés par le service statistique de ma Chancellerie ne sauraient justifier leurs craintes. J'estime, d'autre part, qu'il conviendrait en cette circonstance de rappeler à MM. les jurés qu'ils sont de véritables magistrats, et qu'à ce titre il leur est interdit, conformément aux dispositions de notre droit public, de délibérer par voie de disposition générale sur l'exécution des différentes peines motivées par leurs verdicts ${ }^{39}$.

Contre toute attente, cette initiative eut pour effet de donner à la campagne une impulsion nouvelle. Le jury du Nord contourna ces directives en adressant directement ses vœux au Sénat et à la Chambre des députés, tandis que d'autres firent connaître leurs doléances dans les journaux. La perspective de la clôture du débat parlementaire aidant, le mouvement tendit à se durcir. Avec le temps, on s'achemina, néanmoins, vers une progressive démobilisation (printemps-été 1908), avec les trois rapports du député Castillard favorables à la peine de mort (12 juin, 25 juin, 2 juillet 1908) et en dépit de la résistance opiniâtre de certains jurys et conseils généraux, même après le rejet du projet d'abrogation ${ }^{40}$. 
15 La campagne de pétitions se doubla, par ailleurs, d'une modification de la pratique judiciaire dans le sens d'une punitivité accrue. Si vingt-neuf condamnés à mort attendaient l'issue des discussions en 1906, l'ardeur répressive des jurys déboucha sur une quarantaine de condamnations en 1907-190841. Sur les 49 condamnations capitales prononcées par les Cours d'assises en 1908, 6 furent exécutées. En 1909, 7 condamnés sur 19 furent guillotinés. Nul en 1905-1906, en raison de la politique de grâces systématiques du Président Fallières, le nombre des exécutions capitales atteignit une moyenne annuelle de neuf en 1910-1913 ${ }^{42}$. Conjointement à cette offensive, on assista, de plus, à une vigoureuse campagne de presse de l'un des plus influents quotidiens populaires de l'époque : le Petit Parisien.

\section{La campagne de presse rétentionnniste du Petit Parisien (9 février 1907-5 novembre 1907)}

16 Ce fut dans le contexte des campagnes de presse et d'une vaste politisation du débat que s'ouvrit la discussion à la Chambre des députés. L'augmentation sensible de la délinquance et la survenance de faits divers sordides furent l'occasion pour certains quotidiens de flétrir les carences du gouvernement en matière répressive. Après avoir lancé une consultation le 22 septembre 1907, le Matin contesta l'usage systématique du droit de grâce par le Président Fallières et dénonça le laxisme de l'État. Déjà, le 20 septembre 1907, le Petit Parisien s'était lancé dans la bataille en organisant un "référendum monstre» en vue d'influencer le "législateur». Il est vrai que la mobilisation avait d'autant plus de chance de réussir qu'elle avait été orchestrée très en amont, mais aussi d'une façon particulièrement à même d'intéresser ses lecteurs ${ }^{43}$.

Quotidien de premier plan dès le début du XX $\mathrm{X}^{\mathrm{e}}$ siècle $^{44}$, avec des ventes en progression continue jusqu'en $1915^{45}$, le Petit Parisien avait été créé en 1876, à l'initiative d'un petit groupe d'hommes unis par leur fidélité à l'idéologie républicaine. Composé à l'origine de dix, puis de douze personnalités, son conseil politique rassemblait des avocats et des parlementaires, qui avaient fréquenté les mêmes cercles de pensée (notamment la franc-maçonnerie) et s'étaient liés d'amitié. De la même génération pour la plupart, beaucoup avaient débuté leur carrière à partir de 1848 et rares étaient les novices en politique. Important magnat de la presse, Jean Dupuy (1844-1919), par exemple, cumula ses fonctions de chef d'entreprise avec celles de sénateur, voire de ministre, sous les divers cabinets qui se succédèrent à partir de $1870^{46}$. Conseiller d'affaires connu dans le monde de la finance et du barreau, il avait étendu le champ de ses relations à la sphère politique, fréquentant quelques ténors de la gauche républicaine (Ribot, Rouvier, Waldeck-Rousseau), au point que l'on parla de lui comme candidat potentiel à la Présidence de la République en 1906 et $1913^{47}$. De même, il participa à plusieurs commissions parlementaires tout en s'illustrant comme président du Comité général des associations de la presse française et du Syndicat de la presse parisienne. Défenseur des idées et des intérêts politiques des amis de Dupuy au parlement (ancienne gauche républicaine et membres de l'Alliance démocratique), le Petit Parisien veilla à orienter son public tout en dynamisant ses ventes à travers l'organisation d'opérations de propagande populaire (à coups de feuilletons et de concours) ${ }^{48}$. Sans complaisance pour certaines personnalités de la droite républicaine, il n'affichait pas plus de sympathie pour les radicaux que pour les socialistes. Au moment où les partisans de l'abolition étaient en passe de faire valoir leurs intérêts, l'intervention du journal avait 
précisément pour objet d'inverser la tendance qui se profilait à la Chambre des députés. L'orchestration d'une interminable campagne de sensibilisation (9 février 1907-29 septembre 1907), prélude à la mobilisation, fut suivie d'une consultation populaire, qui en fut comme le point d'orgue et l'aboutissement.

Le quotidien s'empara d'un simple fait divers qu'il construisit comme un événement sensationnel en le centrant sur la figure type du "sadique-assassin-tueur d'enfant ${ }^{49}$, récidiviste, immoral et asocial. Progressivement, il introduisit des considérations mâtinées d'idéologie sur l'évolution sociale, la justice pénale, les fonctions sociales dévolues au châtiment en général, et la peine de mort en particulier, pour mieux procéder au déplacement insidieux de la question de départ à celle, désormais politique, de la peine capitale.

19 Axé sur les effets de la transgression, son discours mettait l'accent sur l'impact social du crime comme atteinte aux normes sociales et l'évolution sociale décadente qu'il tendait à exprimer. Défini par son caractère "odieux", "abominable ", allié aux "circonstancesdramatiques, atroces, révoltantes dans lesquelles la petite Marthe Erbelding trouva la mort $\aleph^{50}$, l'acte était d'autant plus condamnable qu'il n'était pas seulement une violation de la norme pénale : il portait atteinte aux valeurs sociales, s'affirmait comme une négation de la morale de l'élite bourgeoise, que le droit protégeait. Il menaçait la cohésion sociale du groupe et minait ses fondements. Lié à la vision d'une évolution pathologique du social, le crime était l'un des prodromes du pourrissement général de la société, dont le journal se faisait l'écho. Déplacement, extrapolation, dramatisation, servaient la stratégie du quotidien. Le Petit Parisien utilisait la technique de l'amalgame pour accréditer la thèse de la multiplication exponentielle du crime. Influencé par les théories de G. Tarde, il craignait la contamination, par l'imitation, du phénomène criminel. Maladie insidieuse, le crime salissait la société, autant qu'il la dénaturait. Le danger guettait, la menace était partout, latente et incontrôlable, laissant les « citoyens » démunis face à la montée de la violence :

Les malfaiteurs pullulent dans les villes et dans les campagnes: chaque jour, sur tous les points de la France, ils commettent de nombreux attentats dont beaucoup restent impunis [...] le danger du couteau et du revolver nous menace à chaque carrefour, à chaque coin de rue, non seulement quand la nuit est venue, mais dans la pleine clarté du jour ${ }^{51}$.

20 Et les perspectives dépeintes laissaient présager le pire. Toutefois, ce pessimisme n'oblitérait pas toute possibilité ultérieure de redressement moral et social. À cette fin, il fallait lutter contre le crime, plus encore contre le criminel.

21 C'était à travers un discours manichéen, basé sur la construction dichotomique de l'assassin et de la victime, que le journal espérait rallier les partisans de la peine de mort. La gravité de l'acte de Soleilland le jetait dans la bestialité ${ }^{2}$ tout d'abord, l'inhumain ensuite, hors de la société enfin. Ce dernier était ravalé au rang de "bêteimmonde ». "Doté d'une force de criminalité puissante ", c'était essentiellement un «être cruel, au cour dur, dépourvu de bons sentiments, à l'âme insensible, incapable d'aucun

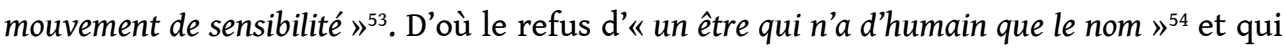
se démarquait, par son caractère aussi asocial qu'immoral, de "ceux qui se défendent, $\grave{a}$ bon droit, d'être ses semblables $»^{55}$. Naturalisé, démonisé, Soleilland apparaissait sous les traits d'un être calculateur, dépourvu de tout scrupule. Se dessinait alors l'idée qu'il n'était pas amendable, qu'il était même peut-être irrécupérable. Ses vices et sa tendance à la récidive signaient l'impuissance de la collectivité à le socialiser. Son passé révélait le mépris dans lequel il tenait les valeurs de la République (travail, mariage, 
famille). Mauvais fils, écolier "peu studieux», vivant dans l'oisiveté et la débauche, mauvais époux et piètre père, Soleilland ne pouvait que passer à l'acte et entériner ainsi son divorce d'avec la société. Il était, dès lors, donné à voir comme un vecteur de danger permanent.

$\mathrm{Au}$ moyen d'un argumentaire tendancieux, le PetitParisien développa un discours idéologique axé sur la critique des institutions de contrôle, l'impuissance de l'État, la déliquescence actuelle. En effet, la recrudescence de la violence n'était nullement à imputer à la police, mais à une justice inféodée aux autorités politiques ${ }^{56}$. De fil en aiguille, le journal opéra un déplacement en direction des véritables responsables du désordre social, passant de la critique du système de justice criminelle à celle de la politique «criminelle » des autorités en place, et plus précisément du gouvernement radical. Le Petit Parisien flétrissait la "faillite de la justice» et dressait le portrait dramatique d'une société qui se délitait, tel « un organisme humain dont un membre est gangrené $\aleph^{57}$. Cependant que "d'un bout à l'autre de notre pays, un cri s'élève, auquel les pouvoirs publics sont impuissants à répondre ${ }^{58}$. Face à de tels «monstres», ni l'emprisonnement, ni les travaux forcés n'étaient à même de satisfaire la fonction d'assainissement social attribuée au système pénal. Le passage dans le milieu carcéral y était rapporté à la douceur de vivre et la sérénité du coupable. Ainsi,

l'assassin de Marthe, on le sait, joue aux cartes avec deux de ses codétenus. La manille et le piquet voleur sont ses jeux préférés. Il dessine également [...] Il a, en sa possession, de nombreux modèles, mais depuis le début de la campagne du Maroc, il s'applique à reproduire - d'après ses souvenirs ou les livres illustrés de la bibliothèque de la prison - des paysages arabes et des guerriers à la physionomie farouche, drapés dans des burnous d'une imposante ampleur et d'une blancheur immaculée $e^{59}$.

Les travaux forcés étaient, quant à eux, associés à des représentations idylliques ainsi qu'à un laxisme que le journal dénonçait. Car la commutation de peine de "l'infâme " Soleilland par le Président Fallières répondait aux vœux du principal intéressé qui "compte être expédié à la Guyane où il espère faire venir sa femme et goûter là-bas une existence paisible $»^{60}$, mais également inviter "son beau frère à venir habiter avec lui, au bagne, dans le chalet qu'il rêve de construire et qu'il entrevoit sous les couleurs les plus riantes ${ }^{61}$.

Si l'état actuel de la situation concourait à conforter l'idée selon laquelle «il n'y a plus de justice ", l'exécution du criminel ne devait pas pour autant s'accompagner d'une publicité jugée malsaine. Paradoxalement, la publicité des exécutions capitales était moins perçue comme un instrument susceptible de montrer l'exemplarité de la peine de mort, que comme un facteur de désordres publics. Le journal demandait que la peine capitale

ne soit pas donnée publiquement, en une sorte d'apothéose lugubre et écoeurante [...] la forfanterie des criminels ne pourrait plus se faire un tremplin de l'échafaud et la morale publique gagnerait, évidemment, à cette discrétion de l'œuvre sanglante ${ }^{62}$.

Bientôt, ce qui n'était qu'allusions furtives à la peine de mort ${ }^{63}$ laissa place à une prise de position ouverte en faveur de la cause rétentionniste.

Ce fut la grâce de Soleilland le 13 septembre 1907, qui servit de détonateur. La construction, puis la mise en scène, de l'« opinion publique "s'opérèrent en deux temps : l'organisation d'une consultation réduite auprès de quelques personnalités ( 28 mars-29 avril 1907), une consultation élargie, qualifiée de "référendum " ${ }^{64}(29$ septembre- 5 novembre 1907). Alors que la manœuvre ne devait durer que du 28 septembre au 25 octobre $1907^{65}$, elle se poursuivit en fait jusqu'au 5 
novembre 1907. Au delà des références explicites et réitérées aux débats de la Chambre des députés, le journal ne cachait pas son souhait de faire pression sur une réforme qu'il désapprouvait. Ainsi,

notre référendum - est-il besoin de le dire? - n'a aucun caractère politique, mais nous serions néanmoins très heureux que nos législateurs, dont beaucoup se sont également émus de la recrudescence des crimes dans notre beau pays de France, en fissent leur profit quand les résultats seront connus, et que le gouvernement tint compte des indications précises qu'il fournira ${ }^{66}$.

\section{Et le Petit Parisien d'ajouter :}

C'est sous la pression de l'opinion publique que, dans la plupart des États, un grand nombre de réformes bienfaisantes sont chaque jour accomplies ${ }^{67}$.

Outre les enjeux politiques, les enjeux financiers n'étaient pas absents. Le « référendum » fut organisé de façon à couvrir l'ensemble du territoire national et étendu à certaines de ses dépendances, l'Algérie notamment, ainsi qu'à des pays étrangers ${ }^{68}$. Les réponses en faveur du «non » étaient très largement favorisées par la campagne de sensibilisation et l'institution de dispositions spéciales de nature à susciter et à orienter les réponses dans le sens recherché. La consultation était, ainsi, doublée d'un "concours artistique ${ }^{69}$, qui consistait à envoyer à la rédaction des "cartes postales illustrées représentant les sites les plus pittoresques de la localité ou de ses environs $»^{70}$, et à l'issue duquel les participants étaient censés remporter de "nombreuses primes de valeur $»^{71}$. Toutefois, la participation au "concours » était subordonnée à certaines conditions d'admission, qui faisaient surtout office de filtres successifs : elles visaient à encourager indirectement la production de réponses rétentionnistes en éliminant les partisans de l'abolition. Ainsi, par exemple,

seuls, nos correspondants appartenant à la majorité donnée par le dépouillement du référendum pourront participer au concours des cartes postales. Les OUI élimineront tous les NON ${ }^{72}$, et réciproquement, selon le résultat final ${ }^{73}$.

Compte tenu de la campagne de sensibilisation qui avait préparé et introduit le "référendum », de la proximité idéologique supposée entre le journal et sa clientèle et de la mise en scène ludique du «concours artistique», le lecteur ne pouvait qu'être enclin à manifester une position rétentionniste, s'il espérait gagner une prime. Le Petit Parisien chercha, de surcroît, à "gonfler» artificiellement le nombre de réponses positives qu'il s'attendait à recevoir par l'instauration d'une disposition spéciale. En effet,

Chaque lecteur ou lectrice ne pourra exprimer qu'une seule fois et individuellement ${ }^{74}$ son opinion. Tous les membres d'une même famille auront la possibilité de la faire chacun sur une carte postale distincte. Les cartes répondant au nom de deux ou plusieurs personnes ou celles qui seraient signées de noms d'emprunt seront éliminées ${ }^{75} d u$ référendum et $d u$ concours artistique ${ }^{76}$.

Outre des allusions prononcées au civisme des lecteurs, le quotidien exhortait ces derniers à une mobilisation rapide :

Dans chacun des départements et dans chaque pays étranger ainsi indiqués [...] par la voie $d u$ Petit Parisien, les cartes devront être mises à la poste le lendemain de l'arrivée du journal de façon à laisser aux lecteurs une journée entière pour préparer leur réponse et leur carte. Le timbre postal fera foi et nous aurons le regret de ne point tenir compte des envois qui seraient en avance ou en retard sur leur série ${ }^{77}$.

La prolongation de l'entreprise était, de plus, destinée à optimiser ses chances de succès. Amorcée le 25 octobre 1907, cette mesure concernait le département de la Seine. Aux mains de la gauche modérée, celui-ci était une force politique de premier 
plan, en raison de sa forte densité démographique et de ses positions sur la peine de mort. C'était la Cour d'assises de la Seine qui avait prononcé la condamnation de Soleilland (24 juillet 1907) et sa grâce s'était suivie d'une offensive des jurys et de leurs alliés dans ce département, d'où l'enjeu considérable que représentait sa mobilisation.

De manière attendue, la publication des résultats ne fit que corroborer la thèse $d u$ journal : sur un total de 1412347 réponses, 1083655 se dégageaient pour le maintien de la guillotine, 328692 contre. Produits de manière à aboutir à un immense "plébiscite", ces résultats permirent au Petit Parisien de se targuer d'une légitimité démocratique susceptible de peser sur la décision d'abroger ou non la peine capitale. Dirigé par des hommes du centre gauche, méfiants vis-à-vis de la politique radicale, le quotidien était clairement un instrument de lutte partisane au service des républicains modérés. À court terme, la mobilisation fut une réussite sur le plan commercial : alors que ses recettes globales s'élevaient à $16780000 \mathrm{~F}$. en 1906, elles se montaient à 18795000 F. en 1908. À moyen terme, la manœuvre participa au renversement du rapport de force et à la victoire des partisans de la peine suprême sur la scène parlementaire. À l'issue de cette campagne d'envergure, la mobilisation en 1908 revêtit un caractère moins intense, moins étendu aussi. Elle fut marquée par l'opposition d'une partie des médecins qui, quoiqu'influente, semblait peiner à se faire entendre.

\section{L'émergence de nouveaux acteurs et discours sur le criminel : la question de la peine de mort vue par les médecins-experts}

33 L'état des infrastructures pénitentiaires ${ }^{78}$, la progression inquiétante de la récidive et le discrédit jeté sur l'institution carcérale comme moyen d'amendement contribuèrent à conforter l'idée que le criminel était incapable de régénération morale ${ }^{79}$. Certes, la transportation semblait plus à même d'enrayer le mouvement ascendant de la récidive et la colonisation pénale présentait l'avantage de s'inscrire dans une conception utilitariste de la sanction, compatible avec une politique d'expansion outre-mer. Mais la relégation avait montré ses limites... Face à l'inefficacité de ces dispositifs, dans un climat dominé par la psychose de larécidive ${ }^{80}$, la peine de mort apparaissait pour les médecins comme l'ultime solution à la crise des pénalités et à son corollaire: le développement d'une criminalité présentée comme générale, galopante et protéiforme, génératrice d'insécurité et porteuse d'une représentation anomique du social.

L'ascension sociale de la fraction supérieure des médecins (dans la société, les prétoires, en politique) avait été encouragée sous l'influence de nouvelles doctrines issues de l'anthropologie criminelle ${ }^{81}$. Conditionnée par leur formation clinique, leur prise de position rétentionniste était aussi liée aux rapports de coopération et de compétition qu'ils entretenaient avec l'élite du barreau dans l'espace politique. Elle était un moyen de prendre part à un débat dont ils se sentaient exclus - en raison de leur position seconde dans les prétoires et au Parlement-, mais sur l'issue duquel ils souhaitaient peser.

Outre une formation médicale, un regard clinique et une pratique professionnelle qui les mettaient quotidiennement aux prises avec la mort, banale à cette époque, ces spécialistes (médecins légistes, médecins militaires, médecins aliénistes) avaient subi l'influence du darwinisme et de l'eugénisme. À un rapport particulier à la mort 
s'ajoutait une conception particulière de la peine capitale. Morale et physique, l'hygiène était un élément prépondérant dans le discours de ces hommes qui écrivaient sur le crime, l'insalubrité et la crémation $^{82}$ et rêvaient d'un vaste projet d'assainissement social, rationalisé par des méthodes scientifiques, gages de rigueur et d'efficacité. D'ailleurs, l'idée de réformes aux vertus curatives était elle-même toute relative, car le déviant revêtait parfois la figure du multirécidiviste, véritable professionnel du crime. Contre celui qui cristallisait la peur des élites bourgeoises et les représentations fantasmatiques d'une insécurité perçue comme le produit d'une société décadente, ces médecins penchaient pour l'élimination pénale, instrument de purification sociale. Paradoxalement, certains en venaient même à envisager le meilleur moyen de donner la mort par une exécution euphémisée, médicalisée, aseptisée. Ce discours savant permit à la strate supérieure des médecins de se poser en experts pour mieux accroître leur sphère d'influence.

Grâce aux récentes découvertes pastoriennes et aux progrès de l'électrothérapie ou de la nouvelle chirurgie, leur importance sociale s'était accrue considérablement. À l'école, ils intervenaient de plus en plus en matière de protection de l'enfance ${ }^{83}$. Avec l'avènement de la médecine du travail et les progrès de l'hygiène, ils s'érigeaient en protecteurs des pauvres ${ }^{84}$.Grâce aux progrès de la médecine légale, quelques-uns étaient parvenus à percer la sphère pénale. Forts de leurs connaissances, ils devenaient experts près les tribunaux, se faisaient les auxiliaires des juges, donnaient leur avis sur la personnalité et la responsabilité du criminel. Par la valorisation de leurs compétences dans ce secteur, ils jouaient un rôle croissant dans le processus judiciaire ${ }^{85}$, alimentant des rapports de concurrence avec les professionnels du droit ${ }^{86}$.

Plus encore, la République ouvrit ses portes aux plus prestigieux d'entre eux ${ }^{87}$. La croyance aux progrès illimités de la science, l'essor du libéralisme parlementaire, la montée en puissance des classes moyennes et le développement de nouveaux moyens (associations médicales, presse spécialisée) avaient favorisé la promotion sociale et politique d'une frange privilégiée de médecins. Fils et représentants d'une bourgeoisie triomphante et sûre d'elle-même, ils étaient issus d'une profession jeune et en plein essor. Présents au sein de l'Exécutif et des assemblées législatives, ils y côtoyaient une majorité d'avocats notoires. Par leur appartenance commune à la sphère publique, tous avaient le sentiment de faire partie d'une même oligarchie politique et sociale. Notabilités provinciales ou nationales, représentants des classes moyennes, les uns et les autres se rencontraient parfois dans les mêmes cercles de pensée ${ }^{88}$. Malgré des divergences sur les vecteurs du progrès social, ces hommes partageaient certaines croyances, adhéraient aux valeurs d'ordre et de progrès véhiculées par l'idéologie républicaine, s'associaient dans le pouvoir pour justifier la mise en œuvre d'une politique de contrôle social accru, la médicalisation de l'enfance, l'élimination de la récidive et la transportation pénale. Productrice d'ordre, l'anthropologie criminelle devait contribuer à promouvoir la morale, la protection de la famille, la défense de l'ordre social, comme l'attestait le vote des lois sur la relégation (27 mai 1885) ${ }^{89}$, la libération conditionnelle (14 août 1885) et le sursis (26 mars 1891) ${ }^{90}$.

Mais en accordant le primat aux facteurs endogènes dans l'explication du crime, les doctrines criminologiques conduisaient à la négation de principes-clés du droit pénal : le libre arbitre et la responsabilité individuelle ${ }^{91}$. Accusées de saper les fondements de la répression, elles étaient jugées dangereuses pour la société et devaient être combattues comme telles ${ }^{92}$. 

ces médecins firent entendre leur voix dans la presse professionnelle (les Archives

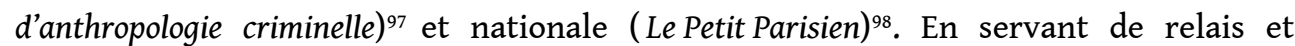
d'amplificateur, l'utilisation d'un quotidien à forte diffusion nationale rendait, il est vrai, plus aisé leur passage d'une tribune restreinte, par son caractère spécialisé, à une autre, plus élargie. Une transition d'ailleurs facilitée par l'adhésion commune du comité éditorial et de la plupart des auteurs à la gauche modérée ${ }^{99}$. A contrario, l'autorité des experts servait le journal, qui cherchait à accroître sa crédibilité, en dépit de son caractère populaire. Ce discours fut d'autant mieux intégré et exploité à des fins de mobilisation, que les représentations des médecins ${ }^{100}$ correspondaient à la vision pessimiste exprimée par le journal.

\section{L'avortement du projet d'abolition sur la scène parlementaire (3 juillet 1908-8 décembre 1908)}

\footnotetext{
Le débat, qui se déroula du 3 juillet au 8 décembre $1908^{101}$, laissa transparaître trois types de considérations : la légitimité de la peine de mort, l'évolution de la criminalité, le pouvoir d'intimidation de la peine capitale.
} 
44 À la mise en cause de la politique gouvernementale et au risque de divisions potentiel au sein du groupe républicain, radicaux et socialistes répondirent par de vibrants appels à l'idéologie partisane. Jaurès (socialiste) expliqua, ainsi, comment l'idéal de progrès des républicains s'était imposé face aux forces de régression en 1789 :

C'est qu'ils [leurs prédécesseurs] n'ont jamais perdu confiance en cette révolution au nom de laquelle ils avaient tué et au nom de laquelle ils étaient tués: Condorcet, proscrit, retraçait les perspectives du progrès indéfini de l'esprit humain, à Robespierre, blessé, on ne pouvait arracher dans son stoïque silence aucune parole de doute et de désaveu. Et c'est parce que ces hommes, à travers la tourmente, ont gardé la pleine espérance, la pleine confiance en leur idéal, qu'ils ont le droit de nous la transmettre et que nous n'avons pas le droit, dans des temps plus calmes, de déserter la magnifique espérance humaine qu'ils avaient gardée. Ce qu'on demande en effet au parti républicain, c'est d'abandonner cette politique d'espérance, cette politique d'humanité; c'est de substituer à cet idéalisme révolutionnaire, considéré comme une chimère creuse et surannée, ce qu'on appelle le réalisme nouveau et qui ne serait que la consécration indéfinie du droit de la force ${ }^{102}$.

Et chacun de rendre hommage aux «héros » de la République pour mieux s'abriter

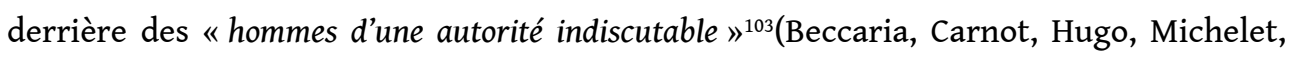
Schœlcher)... tandis que le camp adverse se retranchait derrière la légitimité des grands hommes du temple républicain favorables à la guillotine (Montesquieu, Rousseau, Verlaine, Marat).

La peine capitale était illégitime au regard de la philosophie et de la morale. Injuste et irréparable, elle produisait des effets démoralisateurs ${ }^{104}$. Bien qu'avancé, l'argument du mouvement historique du droit pénal en Europe, des progrès de la science pénale et de la civilisation ne constitua, de même, pas l'axe focal de la stratégie abolitionniste. Si Reinach (radical) voyait dans les progrès de la science pénale le signe inéluctable de la «décadence» de la peine de mort, les rétentionnistes s'opposaient à l'ampleur, au caractère continu, uniforme, homogène et irréversible de ces avancées. Puech (gauche modérée) précisait que

la grande république américaine, l'Autriche-Hongrie, l'Allemagne, l'Angleterre, la Suisse, la Belgique ne rougissent pas de conserver dans leurs codes la peine capitale. Et le député d'expliquer: La vérité, c'est que les grands peuples, les peuples forts, les peuples éclairés conservent la peine de mort, qu'ils appliquent plus ou moins, mais qu'ils considèrent jusqu'ici du moins, comme une menace nécessaire ${ }^{105}$.

Illégitime, la guillotine était, de plus, inefficace, car la criminalité avait des origines sociales. Fustigeant la logique centrifuge de la société industrielle, Dejeante (socialiste) dénonçait cet « amoncellement de ruines sociales " ${ }^{106}$ que représentait l'accroissement du nombre de vieillards, de vagabonds et d'infirmes, auxquels s'ajoutaient l'augmentation de la mortalité liée à la tuberculose et au "fléau de l'alcoolisme » ou encore la «crise du foyer ", la "crisedel'école », la "crise de l'apprentissage » ${ }^{107}$. A contrario, les partisans de la peine de mort voyaient dans la montée de la violence la conséquence d'une évolution délétère, comme en témoignaient l' «affaiblissement général de la moralité » ${ }^{108}$,qu'on imputait à l'école et à la morale laïque, et "l'impuissance de la répression à tous les degrésde l'ordre judiciaire ${ }^{109}$. L'influence des thèses biologiques était perceptible dans le discours de Reinach (radical), qui cita un passage de l'ouvrage de Lacassagne, selon lequel

il est évident que l'alcoolisme est l'une des causes les plus sérieuses de la criminalité. La société et ceux qui la dirigent n'ont-ils pas une grande responsabilité dans le nombre des crimes étranges, commis par des adultes impulsifs, des fils d'ivrognes? Les sociétés ont les criminels qu'elles méritent [...] L'alcool abrutissant la volonté, provoquant l'aboulie, livrant 
le cerveau déséquilibré aux impulsions irrésistibles, nécessairement la responsabilité morale

s'évanouit et n'est plus qu'une fiction ${ }^{110}$. abolitionnistes insistèrent sur la distinction entre grande et moyenne criminalité de sang, meurtres et assassinats, c'est-à-dire entre les crimes passibles de la peine capitale et ceux qui ne l'étaient pas ${ }^{111}$. Avocats pour la plupart, ils mobilisèrent les définitions juridiques qui leur étaient le plus profitables et tentèrent de disqualifier la stratégie adverse, qui consistait à jouer sur l'amalgame en s'appuyant sur une statistique spéciale $^{112}$. Willm (socialiste) accusait les partisans de la peine capitale de prendre en considération l'ensemble des poursuites, quelle que fût leur issue, qu'il s'agisse d'acquittements ou de non-lieux ${ }^{113}$. Alors que Berry (droite nationaliste)soulevait le caractère problématique, incomplet, des statistiques utilisées par le ministre de la Justice, qui ne mentionnaient, selon lui, que les affaires jugées ${ }^{114}$. Briand (radical) posait, quant à lui, la question de la validité des interprétations tirées par les rétentionnistes: les statistiques employées portaient sur un trop petit nombre d'années. Pour Labori et Puech (gauche modérée), il n'en restait pas moins que l'examen des affaires jugées et impoursuivies indiquait une progression constante des crimes de sang ${ }^{115}$. Tributaires de leur formation juridique, point de passage classique pour une carrière politique, aucun ne récusa, cependant, la différenciation juridique introduite par les abolitionnistes. De sorte que le débat porta moins sur la mise en cause de ces catégories que sur leur interprétation.

revanche, tous s'accordèrent sur le caractère malsain des exécutions ${ }^{116}$ et la médicalisation de la déviance. Les socialistes mettaient ainsi l'accent sur l'existence d'une lutte pour la vie ${ }^{117}$, sous l'influence du darwinisme social. Outre la dichotomie criminels d'occasion / professionnels, la notion d'atavisme ${ }^{118}$ fut appelée à contribution pour mieux aboutir à des conclusions opposées. S'ajouta un discours empreint d'une conception pathologique $\mathrm{du}$ social. Que l'on parlât de «maladie», de 《neurasthéniecollective $»^{119}$, « d'atonie $»^{120}$ ou de « langueur », il fallait protéger la société par le renforcement de l'arsenal répressif ici, la mise en œuvre de réformes sociales là.

La discussion s'accompagna, de surcroît, de textes sur la peine de substitution: les propositions Reinach (10 juillet 1906) et Meunier (13 juillet 1906), d'une part; les projets $\mathrm{du}$ gouvernement et de la commission, d'autre part; les contre-projets Ajam (républicain modéré) ${ }^{121}$ et Meunier (radical socialiste) ${ }^{122}$, enfin. Toutefois, l'exploitation de "l'affaire Soleilland" et l'inversion du rapport de force en faveur de la cause rétentionniste entraînèrent le départ de Cruppi (radical) ${ }^{123}$, au profit de Castillard (républicain modéré), et le revirement de la commission ${ }^{124}$.

51 Alors que les propositions Reinach et Meunier soutenaient les travaux forcés, les projets du gouvernement et de la commission convergeaient sur la création d'une peine spécifique d'internement perpétuel. Ils divergeaient, en revanche, sur ses modalités d'application. Le projet du gouvernement prévoyait six années d'encellulement, suivie d'une période de détention à vie dans une maison de force spéciale. Au cours de la première phase, le condamné exécutait sa peine dans l'isolement total (régime de Philadelphie); la seconde phase prévoyait le travail obligatoire le jour et l'isolement la nuit seulement (régime auburnien). La commission, pour sa part, prônait l'exécution du régime auburnien durant toute la durée d'exécution de la peine.

52 L'ensemble de ces initiatives donnèrent lieu à des débats sur les pénalités et l'internement perpétuel. Si, pour les abolitionnistes, c'était la sévérité du bagne et de la

Crime, Histoire \& Sociétés / Crime, History \& Societies, Vol. 6, n | 2002 
relégation, qui était responsable de la hausse de la criminalité, c'était pour les rétentionnistes leur absence de rigueur ${ }^{125}$ qui était en cause. Citant le rapport Cruppi lui-même, Berry (droite nationaliste) constatait qu'« il résulte des statistiques qu'en 1906, à la Guyane, sur un effectif de 6806 transportés, 368 avaient pu s'évader; sur un effectif de 2979 relégués, 852 s'étaient évadés ${ }^{126}$. Et Labori (gauche modérée) de prendre appui sur un passage dudit rapport, suivant lequel

"nous ne savons pas réaliser une vaste réforme pénitentiaire et pénale; nos bagnes sont des foyers putrides, nos prisons départementales sont des centres de corruption, nos lois hésitent, tâtonnent; la récidive augmente et tout l'effort législatif s'est concentré, il y a vingt ans, sur la relégation, mesure qui a échoué1 ${ }^{127}$.

53 Pour mieux conclure :

J'accepterai que les assassins soient envoyés au bagne le jour où vous aurez fait des bagnes, je ne dis pas dont on ne s'évade jamais, car les accidents peuvent se produire partout, mais dont on ne s'évade pas d'une manière périodique, régulière, constante en quelque sorte ${ }^{128}$.

54 Et la réclusion n'était guère plus efficace. Progressivement, on glissa vers la critique de l'ensemble du système pénal pour mettre l'accent sur l'affaiblissement de la répression.Selon Gérard Varet (gauche modérée),

ce bagne d'un nouveau genre se présente avec un caractère de monastère : c'est le monastère des Apaches. Nous voici ainsi menacés de voir se reformer un nouvel ordre religieux, l'ordre des bénédictins de l'assassinat ${ }^{129}$.

55 On remit, par ailleurs, en question l'ensemble du système de justice criminelle en pointant des dysfonctionnements auxquels on attribuait l'augmentation de la grande criminalité pour mieux mettre en évidence l'affaiblissement de la répression et la nécessité «vitale» de maintenir la peine de mort, clé de voûte de l'édifice pénal. En effet,

la relégation, loi de 1880, n'a pas produit les effets espérés; elle a tourné en faillite. Faillite, le bagne avec cette sorte de prestige qui s'attache aux voyages lointains, aux pays ensoleillés, aux grands océans, aux continents mystérieux, avec le mirage surtout des évasions possibles toujours, réelles souvent. Faillite, notre prison centrale, nos maisons de force avec leur souci $d u$ confort qui se dresse comme une douloureuse ironie en face de la misère honnête et vaillante... Faillite également, notre police qui, devant les relâchements à jet continu des parquets, hésite à arrêter. Faillite la police des campagnes, où la gendarmerie impuissante, absorbée par des besognes parasitaires, échoue à maintenir l'ordre, à disperser des bandes de vagabonds, camps volants, comme on les appelle chez nous romanichels, qui sillonnent nos routes, qui tourbillonnent autour de nos villages, rôdent de jour, en qui nos paysans voient et redoutent le voleur et l'incendiaire de nuit ${ }^{130}$.

56 Contrairement à la génération de $1848^{131}$, qui dissociait l'abrogation de la peine capitale du problème de la peine de remplacement, les abolitionnistes de 1908 se placèrent du point de vue de la défense sociale. Loin d'être le signe avant-coureur d'un désinvestissement de l'État en matière de sécurité publique, la peine nouvelle constituait bien l'amorce d'une sécurité accrue ${ }^{132}$. L'internement avait été testé avec succès à l'étranger et son pouvoir d'intimidation avait même été «établi » en France. Pour Briand,

le système de la cellule est pratiqué en France; il a donné des résultats. Autrefois, dans les prisons, nombreux étaient les prisonniers qui attentaient à la vie de leurs gardiens, et quand on les interrogeait, on apprenait, dans la plupart des cas, qu'ils avaient commis leurs crimes pour aller aux travaux forcés, pour être transportés à la Nouvelle-Calédonie. En 1880, une loi est venue décider que, pour ce genre de crimes commis à l'intérieur des prisons, la peine serait subie dans la prison même et dans l'isolement. Dès lors ces crimes ont presque totalement disparu ${ }^{133}$. 

projet fut repoussé par 330 voix contre 201 sur 531 votants. Se mobilisèrent l'ensemble de la droite catholique et conservatrice et de nombreux membres du centre modéré, laïc et républicain (Berry, Castillard, Dansette, Failliot, Folleville, Gioux, Labori, Puech... mais aussi Cochery, Delcassé, Doumer, Péret, Ribot, Roche). Aux socialistes (Allemane, Bedouce, Constans, Dejeante, Jaurès, Meunier, Millerand, Sembat, Vaillant, Viollette) se joignirent les radicaux et les membres du gouvernement (Barthou, Buisson, Caillaux, Doumergue, Pelletan, Reinach, Viviani), de même que certaines personnalités du centre, comme Deschanel, alors que, paradoxalement, certains députés pourtant actifs lors des débats, ne prirent pas part au scrutin (Barrès, T. Reinach).

\section{Conclusion}

Malgré les tentatives de leurs prédécesseurs sous la $\mathrm{I}^{\mathrm{e}}$ et la $\mathrm{II}^{\mathrm{e}}$ Républiques et la reprise du combat abolitionniste sous la III $^{\mathrm{e}}$ République, les efforts des radicaux se soldèrent par un échec, un échec prévisible dès 1907, que le vote de 1908 n'avait fait que consacrer. Pourtant, les propositions en faveur de la suppression des crédits destinés au bourreau, au début de la législature, leur avaient offert une occasion inespérée de réaliser un projet qui leur était cher. L'activisme des partisans de l'abrogation en 1906-1907 semblait, de plus, prometteur. Cependant, le choix du ministre de la Justice et de nombreux abolitionnistes de faire primer la question de la peine de mort sur celle des gages de l'exécuteur constitua une erreur de stratégie génératrice d'effets pervers, puisqu'elle fournit aux détracteurs de l'abrogation l'occasion de mobiliser leurs alliés. La mobilisation rétentionniste, la disparition de Guyot-Dessaigne, puis le revirement de la commission furent autant de facteurs qui pesèrent dans la décision finale de maintenir la guillotine. On peut, néanmoins, se demander si les radicaux étaient réellement désireux de faire aboutir le projet en $1908^{134}$. Outre l'abandon ou l'inachèvement de plusieurs réformes pourtant favorables aux libertés, des lois contraires furent adoptées. Contrairement aux projets de loi sur le divorce ou les syndicats, par exemple, qui furent votés, ceux tendant à modifier le système institutionnel de la III e République n'aboutirent pas, qu'il s'agisse de l'appareil d'État ou des institutions publiques. De l'ambitieux programme de libéralisation des institutions, il ne restait plus grand-chose et l'on peut douter de la réelle volonté des radicaux de procéder à des réformes d'envergure, dès lors que la sécurité publique était en jeu. L'étude de la tentative avortée de 1906-1908 en est un bon exemple. Loin de vouloir un système trop libéral, les radicaux recherchaient l'efficacité, comme l'atteste déjà le programme de Belleville (1869), où Gambetta promettait de débarrasser ses électeurs de la récidive par la relégation. Dans la même veine, J. Reinach avait déposé, en 1906, une proposition prévoyant le remplacement de la peine capitale par les travaux forcés. Quant à Clemenceau, il ne pouvait nullement être accusé d'indulgence, puisqu'il avait sévèrement réprimé les grèves de 1906-1908. Plus encore, au moment où les rétentionnistes commencèrent à se coaliser contre le projet, certains radicaux réaffirmèrent la nécessité de consolider l'arsenal répressif contre les récidivistes par la " guillotine sèche » et la peine capitale. En juillet 1907, en effet, le congrès régional, 
radical et radical-socialiste de Lyon se prononçait pour l'« application stricte de la loi sur les récidivistes, et que les relégués, après la cinquième condamnation, soient envoyés à des travaux utiles aux colonies» et pour «le maintien de la peine de mort avec exécution à l'intérieur des prisons $»^{135}$. Finalement, entre le moment où se dessine un renversement de tendance au profit des partisans de la peine capitale et celui où les débats reprirent en 1908, les radicaux avaient changé d'avis ou étaient, en tout cas, divisés. Si la plupart des acteurs s'accordaient sur la faillite du système répressif et l'échec de la relégation pour enrayer le mouvement ascendant de la récidive, la peine de substitution était un facteur de clivages. L'heure était désormais plus à la répression qu'à l'apaisement. Ce n'est qu'avec la victoire socialiste en 1981 et la reprise du programme radical par Robert Badinter que l'abolition allait connaître son ultime aboutissement, clôturant près de deux siècles de débats récurrents et de tentatives avortées ${ }^{136}$.

\section{BIBLIOGRAPHIE}

Albert J., et al., Histoire générale de la presse, Paris, PUF, tome III (1870-1940), 1972.

Albert P., Histoire de la presse politique nationale au début de la III République, 1871-1879, Lille, Université de Lille III, Paris, Champion, 1980.

Amaury F., Histoire du plus grand quotidien de la III République, le Petit Parisien (1876-1944), Paris, PUF, 1972.

Aubusson de Cavarlay B., Huré M. S., Pottier M. L., Les statistiques criminelles de 1831 à 1981,la base Davido, séries générales, Paris, CESDIP, coll. Déviance et contrôle social, 1989.

Baal G., Histoire du radicalisme, Paris, La Découverte, 1994.

Badinter R., L'abolition, Paris, Fayard, 2000.

Badinter R., Rebérioux M. Candar G., Abolir la peine de mort, le débat parlementaire de 1908, Paris, Société d'études jaurésiennes, 1992.

Blanckært Cl., L'anthropologie des criminels (1850-1900), in Mucchielli L., Ed., Histoire de la criminologie française,Paris, L'Harmattan, 1994, pp. 55-88.

Cannavo C., Le référendum du Petit Parisien sur la peine de mort (novembre 1907), Paris, CFJ, 1970.

Charle Ch., Les élites de la République (1880-1900),Paris, Fayard, 1987.

Charle Ch., Pour une histoire sociale des professions juridiques à l'époque contemporaine, Actes de la recherche en sciences sociales, 1989, CXXVI-CXXVII, 3, pp. 117-120.

Charle Ch., Méritocratie et profession juridique, les secrétaires de la Conférence du stage des avocats de Paris, une étude des promotions 1860-1870 et 1879-1889, Pcedagogica historica, 1994, XXX, 1, pp. 303-324.

Darmon P., Médecins et assassins à la Belle-Époque. La médicalisation du crime, Paris, Seuil, 1989. Debierre Ch., Les deux décapités de Dunkerque, Archives d'anthropologie criminelle,1908, XXIII, pp. 1-19. 
Dubuisson A., Les établissements insalubres de l'arrondissement de Lyon, compte rendu du Conseil d'hygiène publique et de salubrité du département du Rhône, Lyon, Stock, 1891.

Faucher J. A., Jacquemartin N., Le quatrième pouvoir. La presse de 1830 à 1960, Paris, Jacquemart, 1969.

Frajberg M., La peine de mort, l'échec abolitionniste de 1908, mémoire de maîtrise d'histoire, Université de Paris VII, 1982.

Gaudemet J. Y., Les juristes et la vie politique sous la III ${ }^{e}$ République, Paris, PUF, série Science politique, 1970.

Joly H., Le problème pénal au moment présent et la peine de mort, Revue des deux mondes, 1909, XXXXIX, 1, pp. 173-205.

Kalifa D., Insécurité et opinion publique au début du XIX siècle, Les Cahiers de la sécurité intérieure, 1994, 17, pp. 65-76.

Kalifa D., L'encre et le sang. Récits de crimes et société à la Belle Époque, Paris, Fayard, 1995.

Kaluszynski M., La criminologie en mouvement. Naissance et développement d'une science sociale en France au XIX ${ }^{e}$ siècle. Autour des Archives d'anthropologie criminelle d'Alexandre Lacassagne, doctorat d'histoire contemporaine, Université de Paris VII, 3 vol., tomes I et II, 1988.

Kaluszynski M., L'État criminaliste à la fin du XIX siècle ou la rationalisation de la pathologie sociale. Savoir criminologique et usage(s) politique(s), in Lazzeri Ch., Reynie D., Eds., L'homme gouverné,Paris, PUF, 1993a, pp. 1-26.

Kaluszynski M., Savoirs et politiques sur le crime au XIX ${ }^{\mathrm{e}}$ siècle. La morale comme réponse à la question pénale, communication au colloque Ordre moral et délinquance de l'Antiquité au XX $X^{e}$ siècle, SEH/Université de Bourgogne, 7-8 octobre 1993, $1993 \mathrm{~b}$.

Kaluszynski M., Identités professionnelles, identités politiques, médecins et juristes face au crime au tournant du XIX et du XX ${ }^{\mathrm{e}}$ siècles, in Mucchielli L., Ed., Histoire de la criminologie française, Paris, L'Harmattan, coll. Histoire des sciences humaines, 1994a, pp. 215-235.

Kaluszynski M., Sous le regard de l'expert, du technicien et du savant : le criminel à la fin du XIXe siècle, Grenoble, CERAT, $1994 \mathrm{~b}$.

Kaluszynski M., L'incontournable alliance. Savoirs et politiques sur le crime, en France, sous la Troisième République, Sociétés et représentations,1996, pp. 187-197.

Lacassagne A., Base et organisation d'une société de médecine publique, Paris, impr. de V. Goupy, 1877. Lacassagne A., Peine de mort et criminalité, Archives d'anthropologie criminelle, 1908a, XXIII, pp. 57-74.

Lacassagne A., Peine de mort et criminalité, Paris, Maloine, 1908b.

Lacassagne A., Martin E., Des résultats positifs et indiscutables que l'anthropologie criminelle peut fournir à l'élaboration ou l'application des lois, Archives d'anthropologiecriminelle, 1901, pp. 539-542.

Le Beguec G., Un conservatoire d'éloquence parlementaire, la Conférence Molé-Tocqueville à la fin de la III République, Bulletin de la Société d'histoire moderne, 1984, 2, pp. 16-22.

Le Beguec G., L'aristocratie du barreau, vivier pour la République, les secrétaires de la Conférence du stage, $X X^{e}$ Siècle, 1991, 30, pp. 22-32. 
Legrand M. A., La peine de mort et les châtiments corporels appliqués aux criminels. L'opinion des intéressés, Archives d'anthropologie criminelle, 1908, pp. 689-697; également Revue pénitentiaire et de droit pénal, 1909, XXXIII, 2, pp. 288-289.

Léonard J., Les médecins de l'Ouest au XIX'e siècle, doctorat d'État en histoire, 3 vol., Paris, Champion, 1976.

Léonard J., La médecine entre les pouvoirs et les savoirs, Paris, Aubier, coll. Historique, 1981.

Le Quang Sang J., L'abrogation de la peine de mort en France : une étude de sociologie législative (1976-1981), Déviance et Société, 2000, 3, pp. 275-296.

Le Quang Sang J., La loi et le bourreau : la peine de mort en débats (1850-1985), Paris, L'Harmattan, Coll. Logiques sociales, 2001.

Ligou D., Frédéric Desmons et la franc-maçonnerie sous la III République, Paris, Gedalge, 1966.

Lombard F., Notables, citoyens ou incompétents : les représentations des jurés à la lumière de l'histoire du jury,doctorat nouveau régime en sociologie, Paris, EHESS, 1989.

Lombard F., Les jurés, justice représentative et représentations de la justice, Paris, L'Harmattan, coll. Logiques juridiques, 1993.

Machelon J. P., La République contre les libertés ?; les restrictions aux libertés de 1879 à 1914, Paris, FNSP, 1976.

Machelon J. P., L'épuration républicaine, 1970-1871 (Siège et Parquet), 1872-1882 (Parquet), in Assocation Française pour l'Histoire de la Justice, L'épuration de la magistrature de la Révolution à la Libération,Paris, Loysel, 1993, pp. 69-101.

Martinage R., Royer P., Eds., Les destinées du jury criminel, Actes du Colloque de Lille, Villeneuve d'Ascq, L'Espace juridique, 1990.

Martinage R., Royer J. P., Lecocq P., Juges et notables au XIX ${ }^{e}$ siècle,Paris, PUF, 1982.

Mucchielli L., Ed., Histoire de la criminologie française, Paris, L'Harmattan, coll. Histoire des sciences humaines, 1994a.

Mucchielli L., Hérédité et milieu social : le faux antagonisme franco-italien, in Mucchielli L., Ed., Histoire de la criminologie française, Paris, L'Harmattan, coll. Histoire des sciences humaines, 1994b, pp. 189-214.

Nicolet Cl., L'idée républicaine en France (1789-1924), Paris, Gallimard, 1982.

Normand G., L'abolition de la Veuve : l'apothéose infâme,mémoire de DEA d'histoire, IEP Grenoble, 1995.

Nye R.A., Crime, Madness and Politics in Modern France, the Medical Concept of National Decline, Princeton UP, Princeton NJ, 1984.

Padoa Schioppa A., Ed., The Trial Jury in England, France, Germany, 1700-1900,Berlin, Duncker \& Humboldt, 1987.

Perrot M., Ed., L'impossible prison, recherches sur le système pénitentiaire au XIX ${ }^{e}$ siècle, Paris, Seuil, 1980.

Perrot M., Sur la notion d'intérêt de l'enfant et son émergence au XIX ${ }^{\mathrm{e}}$ siècle, Actes,1982, 37, pp. 40-43. 
Perrot M., Robert Ph., Introduction auCommentaire du Compte général de l'administration de la justice criminelle en France pendant l'année 1880 et rapport relatif aux années 1826 à 1880,Genève-Paris, Slatkine-Reprints, 1989, pp. 1-30.

Proal L., Les réformes proposées par l'anthropologie criminelle, Revue pénitentiaire et de droit pénal, 1890, pp. 636-666.

Prud'homme H., La question de la peine de mort devant la Chambre, Revue pénitentiaire et de droit pénal, 1908, XXXII, 11-12, pp. 1324-1342.

Prud'homme H., La question de la peine de mort devant la Chambre, Revue pénitentiaire et de droit pénal,1909, XXXIII, 9, pp. 122-128.

Rebérioux M., La République radicale ? 1898-1914, Paris, Seuil, coll. Points Histoire, 11, 1975.

Reinach J., Ed., Discours et plaidoyers politiques de Monsieur Gambetta, Paris, Charpentier, vol. I, 1880-1885.

Robert Ph., La question pénale,Genève, Droz, 1984.

Schnapper B., Le sénateur Bérenger et les progrès de la répression pénale en France (1870-1914), Annales de la Faculté de Droit d'Istanbul, 1979, 42, pp. 225-251.

Schnapper B., La récidive, une obsession créatrice au XIX ${ }^{e}$ siècle, in Association Française de Criminologie, Le récidivisme, $\mathrm{XX}^{\mathrm{e}}$ congrès de l'Association Française de Criminologie, Poitiers, 7-8-9 octobre 1982, Paris, PUF, 1983, pp. 25-64.

Schnapper B., Le jury en France aux XIX et XX ${ }^{\mathrm{e}}$ siècles, in Schnapper B., Ed., Voies nouvelles en histoire du droit, Paris, PUF, 1991, pp. 241-312.

Tarde G., Sociologie criminelle et droit pénal, Archives d'anthropologie criminelle, 1893, VIII, 47, pp. 513-526.

\section{NOTES}

2. Contrairement aux épisodes de 1791, où le projet fut relié à une réforme pénale (celle qui donna lieu à la création du code pénal révolutionnaire), et de 1848 , où il fut relié à une réforme constitutionnelle (qui consacra l'abrogation de la peine capitale en matière politique et à son remplacement par la détention en enceinte fortifiée), la question fut constituée, comme un problème à part entière et fit l'objet d'un traitement autonome en 1906.

3. C'est-à-dire hostile à l'abrogation de la peine de mort.

4. À une très courte majorité et avec le concours d'abolitionnistes, tels Briand ou Reinach.

5. Nye (1984).

6. Machelon (1976).

7. Ainsi par exemple des lois sur les libertés d'expression, d'association, de réunion, de la presse, etc.

8. Gaudemet (1970).

9. Membres de la gauche modérée, les opportunistes étaient favorables à des réformes tempérées et n'étaient pas opposés à des compromis avec le gouvernement.

10. Schnapper (1983).

11. Notamment le vote de la loi du 30 mai 1854 sur la transportation des criminels aux travaux forcés en Guyane.

12. En 1881, Gambetta prévoyait dans son programme de débarrasser ses électeurs des récidivistes. Waldeck-Rousseau déposa un projet en ce sens le 16 février 1882. Fallières et Devès, 
ministres de la Justice du cabinet Declerck, présentèrent un texte relatif à la relégation des récidivistes et à l'interdiction de séjour pour une partie d'entre eux.

13. C'est-à-dire ceux qui avaient commis plusieurs délits au cours d'une même année ou d'une courte période, Kaluszynski (1996).

14. Alors même qu'elle avait échoué en Australie et que l'Angleterre y avait renoncé en 1859, elle ne fut supprimée en France que le 17 juin 1938.

15. Robert (1984).

16. Kaluszynski (1993 a et b); (1994b).

17. Perrot, Robert (1989), p. 18.

18. Ibid., p. 19.

19. L'expression est de Schnapper, 1983.

20. Formation centriste, née sous l'impulsion de quelques députés de l'Union démocratique, L'Alliance démocratique regroupait bon nombre d'hommes de premier plan (Waldeck-Rousseau, M. Rouvier, J. Caillaux, R. Poincaré, L. Barthou). Ce groupe, qui souhaitait occuper la place vacante entre les deux tendances du parti républicain, était donc concurrencé sur sa droite par les opportunistes et sur sa gauche par les radicaux, pour lesquels il constituait un appoint indispensable. Partisans d'une idéologie du « juste milieu » et tenants d'un certain conservatisme social, ses membres s'opposaient aux radicaux-socialistes, dont ils avaient naguère été les alliés.

21. Comme l'ensemble des républicains, les radicaux s'inscrivaient dans la filiation des principes issus de la Révolution de 1789 (parlementarisme, laïcité de l'État et de l'institution scolaire, libéralisme économique tempéré par de prudentes réformes sociales, patriotisme et défense de l'œuvre coloniale française). Toutefois, les plus modérés (opportunistes) étaient favorables à des réformes mesurées et progressives, tandis que les plus avancés (radicaux, radicaux-socialistes) revendiquaient la mise en œuvre immédiate du programme radical de Belleville. Ce dernier prônait la réalisation de réformes judiciaires, marquées du sceau des libertés: magistrature élective et temporaire, extension du jury à l'ensemble des juridictions, révision des codes et de la détention provisoire, suppression des juridictions d'exception, de la contrainte par corps et de la peine de mort, gratuité et égalité de la justice, indemnisation des victimes, sur l'idéologie radicale, Nicolet (1982), sur le radicalisme, Baal (1994); Rebérioux (1975).

22. L'application de la loi sur les associations, à partir de 1902-1903, fut l'occasion de procéder à la suppression de nombreuses congrégations, à la fermeture d'établissements religieux et à l'expulsion d'ordres notoires. En 1904, les membres des rares congrégations autorisées se virent interdire d'enseigner, l'assistance publique fut laïcisée.

23. Ministre de l'Instruction publique, des Beaux-Arts et des Cultes dans le gouvernement Sarrien (14 mars 1906), il conserva ce portefeuille dans le premier cabinet Clemenceau (1906-1909).

24. L'atmosphère resta tendue. Ce n'est qu'au printemps 1907 que les protagonistes parvinrent à une solution de compromis.

25. L'identité socioprofessionnelle des petits fonctionnaires était déjà déstructurée par une situation et un statut mal définis. L'application des lois Ferry de 1885, la généralisation et la dévaluation du certificat d'études au profit du brevet avaient entraîné leur déclassement social. Ce phénomène, ajouté à la hausse du nombre des prolétaires, avait favorisé leur recrutement accru dans des milieux sociaux proches du prolétariat. La dégradation des conditions de travail, la stagnation du salaire des jeunes cadres depuis 1844 ainsi qu'une politique discrétionnaire en matière d'avancement et de carrière n'arrangeaient rien, bien au contraire.

26. Ainsi, par exemple, des incidents de Cluzes (18 juillet 1904), Longwy (septembre 1905), d'Hennebont (avril-août 1906), de Raon-l'Étape et de Lens (juillet 1907).

27. Section française de l'Internationale ouvrière.

28. Deux fois au ministère de la justice, sept fois au ministère des Affaires étrangères.

29. Il fut vingt-deux fois ministre, deux fois président du Conseil.

30. Lombard (1993). 
31. Un épisode, dont les revues spécialisées se firent l'écho insistant. Ainsi, en particulier, du Journal du ministère public, de la Gazette des tribunaux ou de la Revue pénitentiaireet de droit pénal, dont on connaît les liens étroits avec la Société générale des prisons et la magistrature, cf. Journal du ministère public, 1907, XXXXIX, 1, 161-163; Gazette des Tribunaux, 13 mai 1907; Journal des débats, 15 septembre 1907.

32. Sur l'histoire du jury, Lombard (1989, 1993); Martinage, Royer (1990); Schnapper (1979, 1991), pour une comparaison européenne, Padoa Schioppa (1987).

33. Lombard $(1989,1993)$.

34. Kalifa (1994), p. 71.

35. Ibid., p. 72.

36. Journal des débats, 15 septembre 1907.

37. Le Matin, 16 mai 1907.

38. Kalifa (1994), p. 71.

39. Revue pénitentiaire et de droit pénal, 1907, XXXI, 11-12, p. 1324.

40. En particulier les jurys de la Haute-Loire, de la Seine, de Seine-et-Oise et du Pas-de-Calais. Jusqu'à la fin, des jurys persistèrent à réclamer d'autres réformes, comme la suppression de la publicité des exécutions capitales (jurys de Meurthe-et-Moselle, de la Mayenne, conseils généraux de Meurthe-et-Moselle, du Nord, de la Seine, conseils d'arrondissement de Briey, Toul, Nancy, entre autres) et l'abandon du projet du gouvernement portant réforme des jurys. En 1908, seul le conseil général de la Haute-Vienne émit un vœu favorable à l'abolition de la peine de mort. En 1909 et sur proposition d'un conseiller socialiste, le conseil général du Cher adopta un vœu demandant l'abrogation de la guillotine et son remplacement par l'internement perpétuel, Revue pénitentiaire et de droit pénal, 1908, XXXII, 7-10, p. 1168; Revue pénitentiaire et de droit pénal, 1909, XXXIII, 5, p. 763.

41. Aubusson de Cavarlay, Huré, Pottier (1989), p. 182.

42. Ibid., pp. 95-96, 182.

43. Pour une analyse du « référendum » du PetitParisien, Cannavo (1970).

44. Albert $(1972,1980)$.

45. Sur la presse, Albert (1972, 1980); Faucher, Jacquemart (1969), sur le Petit Parisien, Amaury (1972).

46. Il fut ministre de l'Agriculture (cabinet Waldeck-Rousseau), du Commerce (cabinets Briand, 1909-1910), des Travaux publics (cabinets Poincaré, Briand, Ribot, 1912-1914), ministre d'État et membre du comité de la guerre (cabinet Painlevé, 1917) ainsi que plusieurs fois vice-président du Sénat.

47. Albert (1972).

48. Le nombre de ses faits divers doubla de 10 à 20 relations quotidiennes et leur surface rédactionnelle passa de moins de $8 \%$ à plus de $12 \%$ au cours des années qui précédèrent la Première Guerre mondiale, une progression d'autant plus spectaculaire que la pagination augmenta dans la même période de 4 à 8 pages, Kalifa $(1994,1995)$.

49. L'expression est de Cannavo (1970).

50. Petit Parisien, 21 février 1907.

51. Ibid., 29 septembre 1907, p. 1.

52. Ibid., 24 juillet 1907.

53. Ibid.

54. Ibid., 14 février 1907.

55. Ibid., 14 février 1907.

56. Ibid., 15 septembre 1907.

57. Ibid., 24 juillet 1907.

58. Ibid., 15 septembre 1907.

59. Ibid. 
60. Ibid., 22 juillet 1907.

61. Ibid., 21 juillet 1907.

62. Ibid., 22 avril 1907, pp. 1-2.

63. Ce thème commença à poindre dès le 13 février 1907.

64. Il était, en effet, sous-tendu par une question simple, libellée de la manière suivante : «Êtesvous partisan de la peine de mort? Oui ou non ".

65. Petit Parisien,4 octobre 1907.

66. Ibid.

67. Ibid., 30 septembre 1907.

68. Angleterre, Autriche-Hongrie, Belgique, Danemark, Espagne, Hollande, Italie, Luxembourg, Monaco, Norvège, Portugal, Suède, Suisse.

69. Petit Parisien, 30 septembre 1907.

70. Ibid., $1^{\mathrm{er}}$ octobre 1907.

71. Ibid., 30 septembre 1907.

72. En gras et en capitales d'imprimerie dans le texte.

73. Petit Parisien, $1^{\mathrm{er}}$ octobre 1907.

74. En italiques dans le texte.

75. Idem.

76. Petit Parisien, $1^{\mathrm{er}}$ octobre 1907.

77. En italiques dans le texte, ibid., 2 octobre 1907.

78. Perrot (1980).

79. Lacassagne (1908a); Joly (1909).

80. Schnapper (1983).

81. Blanckært (1994); Kaluszynski (1988); Mucchielli (1994a et b).

82. Dubuisson (1891); Lacassagne (1877).

83. Kaluszynski (1993a, 1994b, 1996); Perrot (1982).

84. Darmon (1989).

85. Kaluszynski (1993a).

86. Ne perdons pas de vue que le corps médical considère les hommes de loi comme un groupe social à la fois rival et voisin: si les liens de famille sont fréquents, les jalousies aussi. Il arrive que les deux milieux se comparent et se confrontent, Léonard (1976).

87. Bert, Cornil, Bertillon, Clemenceau, Combes, entre autres.

88. Les loges maçonniques, par exemple. De sorte que certains médecins furent introduits en politique, moins en tant que spécialistes que comme membres dirigeants de l'un des soutiens du parti radical : le Grand Orient de France, Léonard (1981), sur la franc-maçonnerie, Ligou (1966).

89. Le médecin anthropologue Lacassagne approuvait la loi de relégation, s'il y avait preuve d'une perversité irréductible chez ceux qu'il considérait comme des professionnels du crime, car "les récidivistes, les endurcis sont des antisociaux dont les instincts et les actes répétés peuvent être un danger pour la société. Avons-nous le droit de les reléguer? Nous avons tout au moins le droit de nous défendre contre leurs actions nuisibles ", Lacassagne, Martin (1901), p. 540.

90. Lacassagne se félicita de la loi de 1891 en ces termes : «Ceux qui ont enfreint accidentellement les lois sociales peuvent racheter leur faute. La loi sur le sursis est l'application d'une de ces idées humanitaires que les anthropologistes ont su faire valoir dans leurs études ", ibid.

91. Kaluszynski (1988, 1994a); Proal (1890).

92. La rivalité latente entre la frange supérieure des médecins et celle des hommes de loi transparaît à travers l'opposition artificielle anthropologie criminelle / sociologie criminelle et la recherche de légitimation scientifique du pénal qui lui est liée. Ancien magistrat et partisan des thèses de Lacassagne, Tarde avouait sa préférence pour l'anthropologie criminelle, jugée plus empirique, plus expérimentale, plus en prise avec la réalité. Car, «si légitime que soit l'aspiration de la science sociale à se faire sonroyaume à elle, il ne faut pas qu'elle songe, sous peine de suicide, à se 
retrancher des sciences vivantes, où elle plonge ses racines et puise toute sa force, même celle qu'elle emploie à les repousser parfois. La sociologie, détachée de la biologie, dont elle est la fleur terminale, n'est qu'une fleur coupée, un cadavre décoratif, qui va se desséchant dans les abstractions froides. Cela est surtout vrai de la sociologie criminelle ", Tarde (1893).

93. Charle (1987, 1989); Le Béguec $(1984,1991)$.

94. Ainsi par exemple en politique, mais aussi dans le secteur de la presse, où ils étaient à la croisée des chemins. Alors que les avocats étaient déjà organisés en ordre et avaient accès aux plus hautes fonctions, les médecins avaient du mal à s'unir, et si l'État les intégrait à ses projets, il ne leur était attribué aucun ministère, Kaluszynski, 1994b.

95. Formé en médecine à Strasbourg et à Paris au cours des années 1860-1870, Lacassagne était médecin militaire, professeur de médecine légale à la Faculté de médecine de Lyon en 1880 et promoteur de l'école d'anthropologie criminelle de Lyon.

96. Lacassagne (1908b), p. 57, (1908a), p. 1.

97. Debierre (1908); Lacassagne (1908a); Legrand (1908).

98. LePetit Parisien, 20 février 1907, p. 4; 5 avril 1907, pp. 1 et 2; 19 juillet 1907, p. 1; 5 septembre 1907, p. 2; 9 septembre 1907, p. 1.

99. Kaluszynski (1993b).

100. Lacassagne, par exemple, pour lequel il n'était pas étonnant «qu'actuellement, beaucoup de citoyens se transforment en justiciers parce qu'on n'a plus confiance dans la justice criminelle ». Et ce dernier de dénoncer l'impéritie des hommes politiques et des juges, le laxisme des jurys et le délitement social que de tels dysfonctionnements révélaient, Lacassagne (1908b), p. 75.

101. Badinter, Rebérioux, Candar (1992); Frajberg (1982); Normand (1995); Nye (1984); Prud'homme $(1908,1909)$.

102. J. O., 18 novembre 1908, $2^{\mathrm{e}}$ séance, p. 2394.

103. Intervention de Willm (socialiste), J. O., 4 novembre 1908, $1^{\mathrm{e}}$ séance, p. 2023.

104. J. O., 3 juillet 1908.

105. J. O., 4 novembre 1908, $2^{\mathrm{e}}$ séance, p. 2042.

106. J. O., 11 novembre 1908, $2^{\mathrm{e}}$ séance, pp. 2206-2207.

107. J. O., 7 décembre 1908, p. 2781.

108. J. O., 11 novembre 1908, $2^{\mathrm{e}}$ séance, p. 2217.

109. Ibid.

110. J. O., 3 juillet 1908, p. 1535.

111. La peine de mort ne s'appliquait qu'aux assassinats et aux meurtres spéciaux : les premiers étaient définis comme homicides avec préméditation ou guet-apens (art. 296, CP); les seconds étaient les meurtres avec circonstances aggravantes, donc précédés, accompagnés ou suivis d'un autre crime (art. 301, CP). Le meurtre simple n'était, en revanche, pas passible de la peine capitale, mais des travaux forcés à perpétuité.

112. J. O., 11 novembre 1908, $2^{\mathrm{e}}$ séance, p. 2214.

113. Ibid., 3 juillet 1908.

114. Ibid., 4 novembre $1908,1^{\mathrm{e}}$ séance.

115. Ibid., 4 novembre $1908,2^{\mathrm{e}}$ séance.

116. J. O., 3 juillet 1908, p. 1539; J. O., 11 novembre 1908, $2^{\mathrm{e}}$ séance, p. 2211.

117. J. O., 11 novembre 1908, $2^{\mathrm{e}}$ séance, p. 2206.

118. Pour les criminologues, les origines du crime étaient à rechercher dans les pathologies caractéristiques des criminels. La nature de la société ne faisait que révéler la nature de ceux-ci.

119. J. O., 11 novembre 1908, $2^{\mathrm{e}}$ séance, p. 2217; J. O., 7 décembre 1908, p. 2777.

120. J. O., 18 novembre 1908, $2^{\mathrm{e}}$ séance, p. 2396.

121. Il faisait coexister la peine de mort avec l'internement perpétuel.

122. Selon la décision du jury, la peine nouvelle visait, en fait, à se substituer aux travaux forcés à perpétuité. 
123. Avocat général à la Cour de cassation, député (1898-1919), sénateur radical de HauteGaronne (1920-1924), vice-président de la Chambre en 1906-1907, J. Cruppi (1855-1933) fut appelé à la tête du ministère du Commerce et de l'Industrie le 4 janvier 1908.

124. En juin 1906, elle était composée d'une majorité d'abolitionnistes (Chastenet, Chautemps, Cruppi, Magnaud, Péret, Sembat, Tenting, Viollette). Après 1907, elle changea de président et de rapporteur, Magnaud et Cruppi faisant place aux rétentionnistes Puech (pourtant abolitionniste en 1902) et Castillard. D'où le rejet des propositions Reinach et Meunier par les divers rapports Castillard (12, 25 juin, 2 juillet 1908).

125. Berry (droite nationaliste), par exemple, ibid., p. 2046.

126. Rapport Cruppi, Annales de la Chambre des députés, doc. parl., gème législature, session extraordinaire de 1907, 22 octobre-31 décembre 1907, p. 20.

127. J. O., 4 novembre 1908, $2^{\mathrm{e}}$ séance, p. 2034.

128. Ibid., p. 2046.

129. J. O., 7 décembre 1908, p. 2777.

130. Ibid., p. 2776.

131. Carnot, Garnier-Pagès, Hugo, Lamartine, Ledru-Rollin...

132. Reinach et Deschanel, par exemple, J. O., 3 juillet 1908, p. 1534, J. O., 4 novembre 1908, $2^{\mathrm{e}}$ séance, p. 2043.

133. Ibid., 11 novembre $1908,2^{\mathrm{e}}$ séance, p. 2215.

134. Machelon (1976).

135. Revue pénitentiaire et de droit pénal, 1907, pp. 1104-1105.

136. Sur l'abolition, voir Badinter (2000) et Le Quang Sang (2000, 2001).

\section{RÉSUMÉS}

Au terme de deux siècles de débats récurrents et de vaines tentatives, la peine de mort a été abolie en France le 9 octobre 1981. En dépit de nombreux discours sur cet aboutissement tardif, on connaît moins l'épisode, pourtant essentiel, de 1906-1908. Ce fut en effet sous la III République qu'eut lieu le premier et dernier grand débat d'ensemble sur la question. Ce fut aussi à cette époque que la peine capitale faillit être abrogée, à l'instar de plusieurs autres réformes, favorables aux libertés, prévues dans le programme radical. Cet article tente de mettre en lumière les facteurs qui ont pesé sur le revirement du rapport de force, perceptible dès 1907, au profit des partisans de la guillotine, puis sur le déplacement des enjeux, prélude au rejet du projet, en 1908.

After two centuries of recurring debates and fruitless efforts, the death penalty was abolished in France on 9 October 1981. Despite all that has been written and said about this long-awaited success, less is known about the crucial episode of 1906-1908. It was under the Third Republic that this first and last general debate on the question took place. It was also at this time that the death penalty was almost abrogated, in the wake of several other pro-liberties reforms provided for in the radical platform. The present article attempts to shed some light on the factors that helped swing the balance of power, already perceptible in 1907, towards the partisans of the guillotine, and favored the displacement of the stakes, prelude to the rejection of the project in 1908. 


\section{AUTEUR}

\section{JULIE LE QUANG SANG}

jlqs66@yahoo.fr

Docteur en science politique de l'Université de Paris X, Julie Le Quang Sang est l'auteur d'une thèse sur l'abolition de la peine de mort en France, parue sous le titre La loi et le bourreau : la peine de mort en débats (1870-1985), Paris, L'Harmattan, (2001). Elle a également publié « L'abrogation de la peine de mort en France : une étude de sociologie législative (1976-1981) ", Déviance et Société, $(2000,3,275-296)$. 